\title{
Serological classification of Neisseria gonorrhoeae with monoclonal antibody coagglutination reagents
}

\author{
D V COGHILL, H YOUNG \\ From the STD Diagnostic Laboratory, Department of Bacteriology, University Medical School, Edinburgh
}

SUMMARY A total of 357 clinical isolates of Neisseria gonorrhoeae from 286 patients were classified serologically using two independently developed panels of monoclonal coagglutination reagents. The Pharmacia (Ph) Diagnostics panel comprised 14 reagents, five specific for serogroup WI strains and nine specific for serogroup WII/III strains, whereas the Genetic Systems (GS) panel comprised 14 reagents, seven specific for serogroup WI strains and seven specific for serogroup WII/III strains.

Serogroup WI represented $45 \%$ and WII/III represented $55 \%$ of the patients. Using the monoclonal antibody reagents, the serogroups could be further subdivided into so-called serovars. The $\mathrm{Ph}$ reagents identified four WI serovars and 21 WII/III serovars, whereas the GS reagents identified 10 WI serovars and $18 \mathrm{WII} / \mathrm{III}$ serovars. By combining the results obtained with each panel, $15 \mathrm{Ph} / \mathrm{GS}$ WI serovars and $33 \mathrm{Ph} / \mathrm{GS}$ WII/III serovars were recognised. In the WI isolates, one predominating serovar was recognised, whereas in the WII/III isolates, no single serovar predominated and a much greater variety of serovars was identified. The serovar patterns for men and women patients were very similar, except for one WII/III serovar that was 10 times more common in isolates from men than from women. Most isolates from different anatomical sites in the same patient were of the same serogroup and serovar. Two double infections were found. One patient had a genital infection with serogroup WII/III and a rectal infection with serogroup WI. Another patient with genital, rectal, and throat infections with serogroup WI was found to have gonococci of different GS serovars at each site.

It was concluded that the level of discrimination achieved with the monoclonal antibody reagents should prove to be valuable in studying the microepidemiology of gonococcal infection.

The serological classification of Neisseria gonorrhoeae using polyclonal antibodies directed against protein I epitopes has been in use since $1980 .{ }^{1}$ Using selectively absorbed polyclonal rabbit antisera, Sandstrom and Danielsson were able to divide strains into three antigen classes $\mathrm{W}, \mathrm{J}$, and $\mathrm{M}^{1}{ }^{1}$ Only the $\mathrm{W}$ antigens were found to be suitable for serological classification, and they enabled gonococci to be divided into three serogroups termed, WI, WII, and WIII. These serogroups correlate with the previously described microimmunuofluorescence system ${ }^{2}$ and the subsequently developed protein I enzyme linked immunosorbent assay (ELISA) serotyping system. $^{3}$ The co-

\footnotetext{
Address for reprints: Dr H Young, STD Diagnostic Laboratory, Department of Bacteriology, University Medical School, Teviot Place, Edinburgh EH8 9AG
}

Accepted for publication 4 December 1986 agglutination $\mathrm{W}$ serogrouping system and protein I ELISA serotyping system both detect epitopes on the protein I molecule of the outer membrane of $N$ gonorrhoeae. ${ }^{4}$ Two mutually exclusive protein I molecules are recognised; protein IA molecules that contain the epitopes recognised as serogroup WI, and protein IB molecules that contain the epitopes recognised as serogroups WII and WIII. ${ }^{5}$ Serogroup WIII appears to represent a minor but prominent antigenic variant of protein IB, rather than a third specific moiety. ${ }^{4}$

The W serogrouping system has proved to have important epidemiological and clinical potential. Serogroup WI correlates with resistance to the bactericidal action of normal human serum, ${ }^{6}$ the arginine, hypoxanthine, and uracil requiring $\left(\mathrm{AHU}^{-}\right)$auxotype, disseminated gonococcal infection (DGI), and asymptomatic gonorrhoea. ${ }^{578}$ Serogroup WII/III correlates with resistance to several antimicrobial agents, the mtr mutation, and with homosexually ac- 
quired infection..$^{\text {9-11 }}$ The geographical distribution of serogroups has also been described..$^{81012}$

Unfortunately, reliable and reproducible subdivision of the serogroups is not possible using polyclonal antibodies. Using monoclonal antibodies against gonococcal outer membrane protein $\mathrm{I}$, it is now possible to resolve the two major W serogroups (WI and WII/III) into a large number of serovariants or serovars. ${ }^{1314}$ These monoclonal antibodies have been incorporated in a coagglutination test. Studies to try to establish a panel of standardised coagglutination reagents for the serological classification and identification of $N$ gonorrhoeae have been carried out. ${ }^{813-15}$ Serovar analysis using such a panel has potential in many aspects of gonococcal infection. ${ }^{16}$

To apply serovar analysis to a given epidemiological situation, it is important to know the distribution of gonococcal strains in a community. To date, gonococcal serovar patterns have not been reported from any part of the United Kingdom. This study was undertaken to examine the diversity and distribution of gonococcal serovars in the Edinburgh area and also to compare the classification of isolates with the two panels of reagents.

\section{Patients, materials, and methods}

\section{CLINICAL ISOLATES}

A total of 357 gonococcal isolates were obtained from 286 patients attending the department of genitourinary medicine at the Edinburgh Royal Infirmary from November 1985 to April 1986 inclusive. Initial culture was on modified New York City (MNYC) medium, ${ }^{17}$ and all isolates were identified as $N$ gonorrhoeae by the rapid carbohydrate utilisation test ${ }^{18}$ and the Phadebact monoclonal GC test (Blomqvist et $a l$, unpublished observation presented at 6th International meeting for STD research, Brighton, 1985), which recognises serogroups WI and WII/III separately. Once identified as $N$ gonorrhoeae, isolates were subcultured on to MNYC and clear gonococcal (GC) agar $^{19}$ and incubated for $18-24$ hours at $37^{\circ} \mathrm{C}$ in a moist $10 \%$ carbon dioxide atmosphere for storage and assessment of serovars.

\section{STORAGE OF ISOLATES}

All isolates were stored in $5 \mathrm{ml}$ trypticase soya broth containing $6 \%$ lactose. A sterile cotton swab was used to remove as much growth as possible from an MNYC plate, and the swab was broken off into trypticase soya broth and stored at $-20^{\circ} \mathrm{C}$. Isolates with distinctive or rare serovars and isolates from the same patient but with different serovars were retained for testing again, whereas other isolates were discarded.
SEROVAR IDENTIFICATION

\section{Monoclonal coagglutination reagents}

Serovars were identified using two different sets of monoclonal coagglutination reagents obtained from Genetic Systems (GS) and Pharmacia (Ph). ${ }^{15}$ Both sets of reagents were kindly supplied by Dr $S$ Bygdeman, Huddinge University Hospital, Stockholm, Sweden. The GS reagents consisted of seven WI reagents (Af, $\mathrm{Ae}, \mathrm{Ad}, \mathrm{Ag}, \mathrm{Ak}, \mathrm{Ai}$, and $\mathrm{Ah}$ ) and seven WII/III reagents $(\mathrm{Ba}, \mathrm{Bc}, \mathrm{Be}, \mathrm{Bg}, \mathrm{Bh}, \mathrm{Bj}$, and $\mathrm{Bk})$, and the $\mathrm{Ph}$ reagents consisted of five WI reagents (Ar, Ao, As, At, and Av) and nine WII/III reagents $(\mathrm{Br}, \mathrm{Bo}, \mathrm{Bp}, \mathrm{By}, \mathrm{Bu}, \mathrm{Bv}, \mathrm{Bs}, \mathrm{Bt}$, and $\mathrm{Bx})$.

\section{Antigen preparation}

Isolates were incubated for 18-24 hours on GC medium. Using a cotton swab, they were harvested into $1 \mathrm{ml}$ phosphate buffered saline $\mathrm{pH} 7 \cdot 2$ to give a smooth milky suspension. This suspension was boiled for 10 minutes and allowed to cool before testing. Prepared antigen was stored at $4^{\circ} \mathrm{C}$ for up to two weeks if not tested immediately.

\section{Test procedure}

Monoclonal coagglutination reagents and antigen preparations were each mixed well before testing. The tests were carried out by adding $20 \mu$ l of prepared antigen suspension to $20 \mu \mathrm{l}$ of each coagglutination reagent on defined areas of surface treated plastic plates (Bioplate Type II, Biotest Folex Ltd, Moseley, Birmingham, England). Plates were rocked gently for two minutes, and coagglutination reactions were read using an oblique light against a dark background. Included with each set of reagents was a control containing antigen only, to check for autoagglutination.

\section{Scoring results}

Reactions were scored according to the strength of the coagglutination observed. They were graded negative (-) if they showed a smooth milky background; borderline $( \pm)$ if they showed a slightly granular milky background; weakly reactive $(1+)$ if they showed a granular background with some clearing; or moderately reactive $(2+)$, strongly reactive $(3+)$, or very strongly reactive $(4+)$ if they showed increasing degrees of clumping and background clearing.

\section{Designation of serovars}

A serovar is defined as the pattern of reactivity of a test strain with a given set of monoclonal antibodies specific for either the WI or WII/III serogroup. ${ }^{20}$ Each serovar is therefore depicted by an upper case letter A if it belongs to serogroup WI and a B for WII/III isolates; these letters are then followed by lower case letters representing positive-reactions with the corresponding coagglutination reagents. ${ }^{13}$ Reac- 
tions of $1+$ or more were scored as positive in designating a strain to a serovar.

\section{Retesting isolates}

Isolates that gave borderline reactions and those that autoagglutinated were grown again from storage in trypticase soya broth and retested. Isolates from multiple anatomical sites in the same patient that were shown to belong to different serovars were grown again from storage in trypticase soya broth, and 10 colonies from each site were tested to investigate the possibility of a mixed infection.

\section{Results}

A total of 357 gonococci was isolated from 264 genital (urethral, cervical, or both), 61 rectal, and 32 pharyngeal cultures. Gonococci of serogroup WI were isolated from $62(37 \%)$ and WII/III from 107 $(63 \%)$ of 169 infected men. Serogroup WI gonococci were isolated from $67(57 \%)$ and WII/III from 51 $(43 \%)$ of 117 infected women (one with a WI and a WII/III strain). Gonococci were isolated from both genital and extragenital (rectal, pharyngeal, or both) sites in $49(42 \%)$ women and in $14(8 \%)$ men. Except in the woman infected with both serogroups (WI rectally and WII/III genitally), gonococci isolated from different anatomical sites in the same patient were of the same serogroup.

\section{WI ISOLATES}

The distribution of $\mathrm{Ph}$ and GS serovars in the 129 patients infected with WI isolates is given in tables 1 and 2. One predominating serovar (Ph-Arost and GSAedgkih) was seen with each set of reagents. The isolates could be divided into four $\mathrm{Ph}$ serovars and 10 GS serovars. The four most commonly occurring GS serovars, however, comprised $98 \%$ (61) of isolates from men and $88 \%(59)$ of isolates from women. Other GS serovars were usually represented by only one or two strains.

Table 3 gives the correlation between $\mathrm{Ph}$ and GS serovars in the WI isolates. The predominating $\mathrm{Ph}$
Table 1 Distribution of Ph serovars in WI isolates from 62 men and 67 women

\begin{tabular}{llr}
\hline & \multicolumn{2}{l}{ No $(\%)$ infected with serovar } \\
\cline { 2 - 3 } Serovar & Men & Women \\
\hline Arost & $46(74)$ & $48(72)$ \\
Arst & $9(15)$ & $10(15)$ \\
Aros & $2(3)$ & $6(9)$ \\
Av & $5(8)$ & $3(5)$ \\
Total & 62 & 67 \\
\hline
\end{tabular}

Table 2 Distribution of GS serovars in WI isolates from 62. men and 67 women

\begin{tabular}{llr}
\hline & \multicolumn{2}{l}{ No $(\%)$ infected with serovar } \\
\cline { 2 - 3 } Serovar & Men & Women \\
\hline Aedgkih & $46(74)$ & $46(69)$ \\
Aedgki & $1(2)$ & $1(2)$ \\
Aedgk & $3(5)$ \\
Aedg & $2(3)$ & $4(6)$ \\
Aegk & & $4(6)$ \\
Adg & & $1(2)$ \\
Agk & & $1(2)$ \\
Aedgih & $8(13)$ & $2(3)$ \\
Aedih & $5(8)$ & $5(8)$ \\
Ae & 62 & $2(3)$ \\
Total & $69^{*}$ \\
\hline
\end{tabular}

*Multiple isolates from one patient gave slightly different serovars: Adg from cervix; Aedg from rectum; and Aedgk from fauces.

serovar correlated well with the predominating GS serovar, this combination accounting for $68 \%$ (89) of the 129 patients infected with WI isolates. Fifteen different combinations were recognised. Six of the 10 GS serovars each corresponded to only one $\mathrm{Ph}$ serovar, but only one of the four $\mathrm{Ph}$ serovars corresponded to one GS serovar (Av/Ae). In one woman with a WI infection, isolates from multiple anatomical sites each had slightly different GS serovars. The serovars remained different when tested again. In all other patients infected at multiple sites with WI isolates, the $\mathrm{Ph}$ and GS serovars of isolates from each site were identical.

Table 3 Correlation between Ph and GS gonococcal serovars in WI isolates from 129 patients

\begin{tabular}{|c|c|c|c|c|c|c|c|c|c|c|c|}
\hline \multirow{2}{*}{$\begin{array}{l}\text { Ph } \\
\text { serovars }\end{array}$} & \multicolumn{11}{|c|}{ GS serovars } \\
\hline & Aedgkih & Aedgki & Aedgk & Aedg & Aegk & $A d g$ & $A g k$ & Aedgih & Aedih & $A e$ & Total \\
\hline $\begin{array}{l}\text { Arost } \\
\text { Arst } \\
\text { Aros } \\
\text { Av }\end{array}$ & $\begin{array}{r}89 \\
2\end{array}$ & 1 & $\begin{array}{l}3 \\
1\end{array}$ & $\begin{array}{l}1 \\
2 \\
1\end{array}$ & $\begin{array}{l}1 \\
5\end{array}$ & 1 & 1 & 2 & 13 & 8 & $\begin{array}{r}94 \\
21 \\
8 \\
8\end{array}$ \\
\hline Total & 91 & 1 & 4 & 4 & 6 & 1 & 1 & 2 & 13 & 8 & $131^{*}$ \\
\hline
\end{tabular}

*Multiple isolates from one woman patient gave slightly different GS serovars 
Table 4 Distribution of $P h$ serovars in WII/III isolates from 107 men and 51 women

\begin{tabular}{lrr}
\hline & \multicolumn{2}{l}{$N o(\%)$ infected with serovar } \\
\cline { 2 - 3 } Serovar & Men & Women \\
\hline Bropt & $38(36)$ & $21(41)$ \\
Bropv & $4(4)$ & $2(4)$ \\
Brop & $21(20)$ & $3(6)$ \\
Bro & $1(1)$ & $1(2)$ \\
Bropyt & $2(2)$ & $1(2)$ \\
Bropyst & $1(1)$ & \\
Broput & $1(1)$ & \\
Brot & $2(2)$ & $1(2)$ \\
Bo & $1(1)$ & $1(2)$ \\
Bopt & $1(1)$ & \\
Bopyt & $3(3)$ & \\
Bopst & $1(1)$ & $11(22)$ \\
Brpt & $17(16)$ & $3(6)$ \\
Brpyst & $1(1)$ & $1(2)$ \\
Brpyust & $5(5)$ & $4(8)$ \\
Brpyut & $1(2)$ \\
Bpyvut & $1(8)$ & 1 \\
Bpyust & & 51 \\
Av/Bx & & \\
Av/Bpsx & 107 & \\
Av/Bpsux & & \\
Total & & \\
\hline
\end{tabular}

\section{WII/III ISOLATES}

The distribution of $\mathrm{Ph}$ and GS serovars in the 158 WII/III isolates is given in tables 4 and 5. There was a greater variety of WII/III Ph and GS serovars than WI serovars. The WII/III isolates consisted of $21 \mathrm{Ph}$ serovars and 18 GS serovars. The serovars (Ph-Bropt and GS-Bajk) occurring most commonly with each panel of reagents did not predominate to the same extent as the WI predominating serovars.

The prevalence of $\mathrm{Ph}$ and GS serovars was comparable in men and women, except that Ph-Bropyt and GS-Back were 10 times more prevalent in men than women. Table 6 shows the correlation between $\mathrm{Ph}$ and GS serovars in the $158 \mathrm{WII} / \mathrm{III}$ isolates. The most common combination, which accounted for $32 \%(50)$ of the WII/III isolates, corresponded to the most common $\mathrm{Ph}$ and GS serovars.

Thirty three WII/III combinations were recognised, over twice the number recognised in WI isolates. Sixteen of the $21 \mathrm{Ph}$ serovars each corresponded to only one GS serovar, the most notable of these being the $\mathrm{Av} / \mathrm{Bx} / \mathrm{Behj}$ combination. Nine of the 18 GS serovars each corresponded to one $\mathrm{Ph}$ serovar.

In all patients infected at multiple sites with WII/III isolates, the $\mathrm{Ph}$ and GS serovars of isolates from each site were identical.

\section{Discussion}

Using monoclonal coagglutination reagents, the distribution of serogroup WI was found to be $45 \%$ and of WII/III was $55 \%$. This distribution was consistent
Table 5 Distribution of GS serovars in WII/III isolates from 107 men and 51 women

\begin{tabular}{lrr}
\hline & \multicolumn{2}{c}{$N o(\%)$ infected with serovar } \\
\cline { 2 - 3 } Serovar & \multicolumn{1}{c}{ Men } & Women \\
\hline Baj & $7(7)$ & $5(10)$ \\
Bajk & $38(36)$ & $17(33)$ \\
Bacjk & $3(3)$ & $3(6)$ \\
Back & $21(20)$ & $1(2)$ \\
Bak & $2(2)$ & $1(2)$ \\
Bacej & $12(11)$ & $2(4)$ \\
Bacejk & $3(3)$ & $2(4)$ \\
Bacehjk & $2(2)$ & \\
Baehjk & $1(1)$ & \\
Baeghjk & $1(1)$ & $1(2)$ \\
Baej & $4(4)$ & \\
Baejk & $2(2)$ & $3(6)$ \\
Bcegjk & $1(1)$ & $6(12)$ \\
Bceghjk & $1(1)$ & $3(6)$ \\
Bcgjk & $8(8)$ & 51 \\
Beghjk & $1(1)$ & \\
Behj & 107 & \\
Bj & & \\
Total & & \\
\hline
\end{tabular}

with that found in a previous study employing polyclonal antibody reagents. ${ }^{11}$ These results are also similar to findings in Scandinavia, where WII strains were shown to predominate in larger towns and WI strains predominated in the smaller towns. ${ }^{821} \mathrm{We}$ compared serogroup patterns between strains isolated from men and women. Of isolates obtained from 169 men, $37 \%$ belonged to serogroup WI and $63 \%$ to serogroup WII/III, and of isolates obtained from 117 women, $57 \%$ belonged to serogroup WI and $43 \%$ to serogroup WII/III. These results are consistent with previously reported Scandinavian data in which WI strains were more common in strains isolated from women than men. ${ }^{8}$

Strains belonging to serogroup WI could be resolved into four Ph serovars and 10 GS serovars, with a total of $15 \mathrm{Ph} / \mathrm{GS}$ serovar combinations. Serogroup WII/III isolates could be resolved into $21 \mathrm{Ph}$ serovars and $18 \mathrm{GS}$ serovars, with a total of $33 \mathrm{Ph} / \mathrm{GS}$ serovar combinations. When one serovar in one system corresponded to two or more serovars in the other system, the latter were closely related, reaction patterns differing in only one or two reagents.

The $\mathrm{Ph}$ and GS reagents used in this study and four additional GS reagents (two specific for WI and two for WII/III) have been used to identify strains, mostly obtained from northern Europe and the United States of America, in a worldwide epidemiological study. ${ }^{20}$ Isolates belonging to serogroup WI could be resolved into $12 \mathrm{Ph}$ serovars and $21 \mathrm{GS}$ serovars. Isolates belonging to serogroup WII/III could be resolved into $38 \mathrm{Ph}$ serovars and $62 \mathrm{GS}$ serovars. A total of $27 \mathrm{WI}$ $\mathrm{Ph} / \mathrm{GS}$ serovar combinations and $93 \mathrm{WII} / \mathrm{III} \mathrm{Ph} / \mathrm{GS}$ serovar combinations were recognised. The larger 
Table 6 Correlation between Ph and GS serovars in 158 WII/III isolates

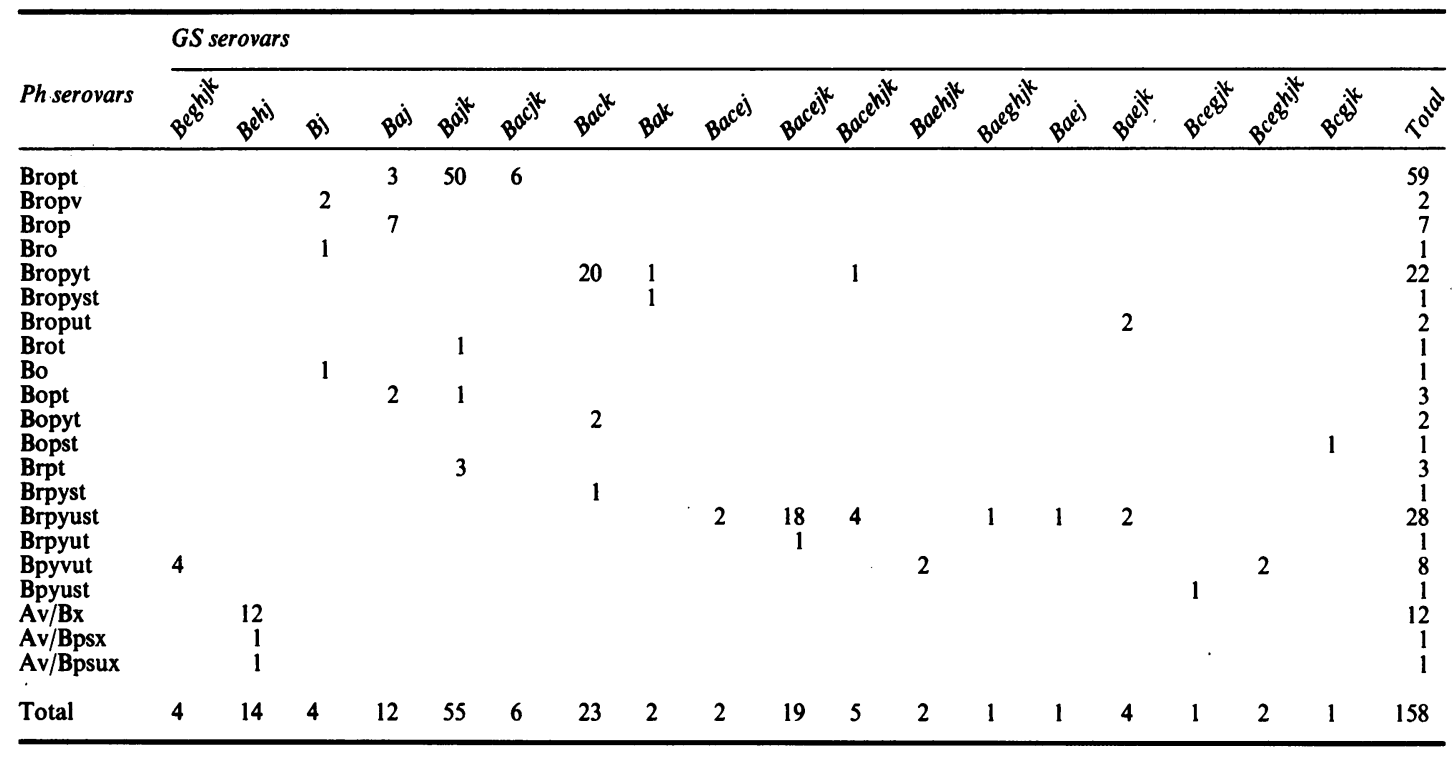

numbers of serovars recognised in such a worldwide study compared with a more localised study suggest that a large variety of different strains is circulating in different geographical locations.

A similar study carried out on strains isolated from Australia, New Zealand, Bangkok, Singapore, and Korea resolved 165 WI strains into seven Ph serovars, seven GS serovars, and eight $\mathrm{Ph} / \mathrm{GS}$ serovar combinations; and 395 WII/III strains resolved into $25 \mathrm{Ph}$ and 19 GS serovars with $41 \mathrm{Ph} / \mathrm{GS}$ serovar combinations. ${ }^{16}$ Several additional studies using selected panels of these $\mathrm{Ph}$ and GS reagents have been reported. $^{814-162022-24}$ These include studies that compared the discriminatory power of each panel $^{1520}$ and showed varying numbers of different serovars in the gonococcal populations studied.

Serovar patterns in the two major serogroups (WI and WII/III) differed noticeably. Strains belonging to serogroup WII/III could be subdivided into more serovars than strains belonging to serogroup WI. This has been noted in previous studies. ${ }^{81620}$ One serovar combination (Arost/Aedgkih) was found to predominate in the WI isolates. This was consistent with data reported in a worldwide study. ${ }^{1620}$ The important foci of this serovar combination are thought to be Europe, North America, and some parts of Australia, but not South East Asia. ${ }^{16}$ Bygdeman reported that the GS serovars Aedgkih, Aedih, and Ae were the three most common serovars in 533 isolates from different geographical areas, and accounted for $92 \%$ of the isolates. ${ }^{16}$ These serovars were also the most common serovars in WI isolates from Edinburgh, accounting for $85 \%$ of the isolates. In a survey of serovars of gonococcal isolates from different parts of the world, 13 WI serovars were recognised, $59 \%$ of which were accounted for by the GS serovars Aedgkih, Aedih, and Ae. ${ }^{24}$ The geographical origin of these isolates, however, was not reported.

No predominating serovar was recognised in strains belonging to serogroup WII/III. This observation has been made in previous studies. ${ }^{1620}$ In the same survey as that described for WI strains, Bygdeman reported that $1333 \mathrm{WII} / \mathrm{III}$ strains could be resolved into 36 GS serovars. ${ }^{16}$ The 10 most common serovars (Bajk, Bacejk, Bak, Bacek, Bacjk, Bcgjk, Back, Beghjk, Bcegjk, and Bcgk) accounted for $98 \%$ of the WII/III isolates. In the present study WII/III strains from 158 patients could be resolved into 21 GS serovars. The 10 most common serovars (Bajk, Bacejk, Bacjk, Back, Beghjk, Behj, Bj, Baj, Bacehjk, and Baejk) accounted for $92 \%$ of the WII/III isolates. Five of these serovars are included amongst the 10 most common WII/III serovars reported by Bygdeman. ${ }^{16}$ These findings support the observation made by Bygdeman that there are great differences in WII/III serovar patterns between different regions, and that the serovar Bajk is common to all geographical regions. ${ }^{16}$ One WII/III serovar combination (Bropyt/Back) is notable by the observation that strains of this serovar are 10 times more often isolated from men than women. As serogroup WII/III has been correlated with homosexually acquired infection, ${ }^{91125}$ this serovar is probably related to homosexuality. 
The small variety of serovars noted in isolates belonging to serogroup WI could be a result of the poor discriminatory power of the WI monoclonal antibodies or, alternatively, could reflect the small number of different epitopes of protein IA. The latter possibility would suggest the need for an alternative target antigen to protein I for use in the serological classification of WI strains. Sandstrom et al found it more difficult to obtain different antibodies against WI epitopes than WII/III epitopes, ${ }^{14}$ and studies on the antigenic drift of gonococcal protein I suggest that the WI serogroup is more antigenically stable than the WII/III serogroup. ${ }^{20}$ Auxotype analysis has been combined with serovar analysis to try to improve the resolution of the serovar system. ${ }^{23} 26$ Although several correlations between auxotype and serovar have been reported, ${ }^{162324}$ these studies show that the combination of serological classification with auxotyping achieves greater discrimination than if either system is used alone. Auxotyping, however, is not as easy to perform as serogrouping by coagglutination, and its use is therefore more restricted.

Despite the limitations, the degree of discrimination achieved by serological classification alone has proved valuable in many aspects of gonococcal epidemiology and pathogenesis. Serovar analysis has proved useful in contact tracing. In a study by Backman et al, gonococcal strains from $95 \%$ of known contact pairs belonged to the same serovar in each couple. ${ }^{27}$ Non-matching serovars from presumed sexual partners indicate that additional partners may have to be traced, or that there are double infections. The occurrence of double infections can be assessed by serovar analysis. Double infections were rare in this locality. One woman (less than 1\%) out of 117 was infected simultaneously with gonococcal strains of different serogroups at each site. Another woman was infected with gonococci belonging to slightly different GS serovars at each site. Backman et al reported that two $(1 \%)$ of 218 women, two $(7 \%)$ of 28 heterosexual men, and three $(25 \%)$ of 12 homosexual men had two or more gonococcal isolates simultaneously. ${ }^{27}$ These workers drew attention to the problem of recognising a double infection at one site with strains belonging to the same serogroup but different serovars.

Serovar analysis has great potential for the control of microepidemics of gonococcal infection, particularly with a strain with a distinctive serovar or one that has low prevalence in the population. In this study, a distinctive strain that cross-reacted with $\mathrm{Ph}$ $\mathrm{Av}$ and $\mathrm{Ph} \mathrm{Bx}$ reagents was detected in $14(5 \%)$ of infected patients. All these strains belonged to GS serovar Behj and, furthermore, this serovar was found uniquely in such strains. A worldwide study reported that no isolates reacted with the $\mathrm{Ph} \mathrm{Bx}$ reagent. ${ }^{15}$ More recently, however, the same $\mathrm{Av} / \mathrm{Bx}$ cross reactive strains have been reported. ${ }^{16}$ These strains were also found to cross react with the GS Al reagent, one not included in the panel used in the present study. It has been proposed that these strains are the missing link between serogroups WI and WII/III. ${ }^{16} \mathrm{We}$ are currently monitoring all $\mathrm{Av} / \mathrm{Bx}$ isolates and carrying out intensive contact tracing to prevent this serovar becoming more widely established in the community.

Serovar analysis has potential value in medicolegal cases, particularly when the serovar of tested strains is related to the prevalence of such strains in the geographical area concerned. ${ }^{16}$ Serovar analysis has also been found to facilitate the classification of isolates taken before and after treatment as representing treatment failure or reinfection. ${ }^{1628}$

Correlations between serovars and various aspects of gonococcal infection extend the potential value of serovar analysis. These correlations include an association between serovar and susceptibility to antibiotics, ${ }^{162829}$ serovar and sexual preference, ${ }^{27}$ and serovar and auxotype. ${ }^{162324}$ Auxotype $\mathrm{AHU}^{-}$, which was previously correlated with disseminated gonococcal infection, ${ }^{7}$ has been correlated with particular serovars, indicating that serovar analysis could prove useful in identifying strains capable of causing serious or complicated infections. Serovar and auxotype analysis have also been correlated with plasmid profile, ${ }^{16}$ and serovar analysis has potential for monitoring outbreaks of infection with penicillinase producing strains of Neisseria gonorrhoeae (PPNG), thus helping to control such infections in the community. ${ }^{1530} \mathrm{~A}$ knowledge of PPNG serovars allows outbreaks to be recognised early and contact tracing efforts to be concentrated on people infected with the epidemic strain. ${ }^{16}$ The loss of the $\beta$ lactamase encoding plasmid from PPNG strains has been reported. ${ }^{16}$ Serovar analysis could therefore have an advantage over detection methods that rely on production of the $\beta$ lactamase enzyme to identify PPNG strains, in that the spread of infection could continue to be monitored, even when one or more of the contacts in the chain of infection are infected with gonococci that have lost their $\beta$ lactamase plasmid.

The diversity of antigenic types of gonococci circulating in the Edinburgh area were illustrated in this study. To date, there are no published data on serovar patterns in the United Kingdom. A knowledge of currently existing serovars in a particular geographical area is necessary to interpret results obtained from serovar identification. Monitoring strains by serovar identification should also prove useful in developing antigen detection systems and in evaluating the use of monoclonal antibodies for serological classification. 
Continued monitoring of serovar patterns will be necessary, as temporal changes may occur because of genetic alteration of existing strains and the importation of strains from different geographical regions.

Serovar analysis by the coagglutination test is an easy and reproducible method for classifying gonococci. Although resolution could be improved by incorporating additional reagents to the panel, a compromise must be reached between improving resolution and making serovar analysis too complex and time consuming. The temporal monitoring of strains in particular geographical regions should make it possible to design panels suitable for the different regions, as the range of gonococci in any one area is limited. ${ }^{8}$ A standardised panel, however, would be preferable to compare results from around the world. Local monitoring of serovar patterns from geographical regions around the world should allow the origin of outbreaks to be identified and the worldwide spread of gonorrhoea to be studied.

DVC gratefully acknowledges receipt of a Faculty of Medicine Scholarship. The work was supported by a Scottish Home and Health Department research grant $\mathrm{K} / \mathrm{MRS} / \mathbf{5 0 / C 8 7 5}$. We are indebted to Dr Solgun Bygdeman for her helpful advice and infectious enthusiasm.

\section{References}

1 Sandstrom E, Danielsson D. Serology of Neisseria gonorrhoeae. Classification by coagglutination. Acta Pathol Microbiol Scand [B] 1980;88:27-38.

2 Wang SP, Holmes KK, Knapp JS, Ott S, Kyzer DD. Immunological classification of Neisseria gonorrhoeae with microimmunofluorescence. J Immunol 1977;119:795-803.

3 Buchanan TM, Hildebrandt JF. Antigen-specific serotyping of Neisseria gonorrhoeae: characterisation based upon principal outer membrane protein. Infect Immun 1981;32: 985-94.

4 Sandstrom EG, Knapp JS, Buchanan TM. Serology of Neisseria gonorrhoeae: W-antigen serogrouping by coagglutination and protein I serotyping by enzyme-linked immunosorbent assay both detect protein I antigens. Infect Immun 1982;35:229-39.

5 Sandstrom EG, Chen KCS, Buchanan TM. Serology of Neisseria gonorrhoeae: coagglutination serogroups WI and WII/III correspond to different outer membrane protein I molecules. Infect Immun 1982;38:462-70.

6 Hildebrandt JF, Mayer LW, Wang SP, Buchanan TM. Neisseria gonorrhoeae acquire a new principal outer membrane protein when transformed to resistance to serum bactericidal activity. Infect Immun 1978;20:267-73.

7 Hildebrandt JF, Buchanan TM. Identification of an outer membrane protein associated with gonococci capable of causing disseminated infection. In: Brooks GF, Gotschlich E, Holmes K, Sawyer W, Young F, eds. Immunobiology of Neisseria gonorrhoeae. Washington DC: American Society for Microbiology, 1978:138.

8 Bygdeman S, Danielsson D, Sandstrom E. Gonococcal W serogroups in Scandinavia: a study with polyclonal and monoclonal antibodies. Acta Pathol Microbiol Scand [B] 1983;91:293-305.
9 Morse SA, Lysko PG, McFarland L, et al. Gonococcal strains from homosexual men have outer membranes with reduced permeability to hydrophobic molecules. Infect Immun 1982; 37:432-8.

10 Bygdeman S. Antibiotic susceptibility of Neisseria gonorrhoeae in relation to serogroups. Acta Pathol Microbiol Scand [B] 1981; 89:227-37.

11 Reid KG, Young H. Serogrouping Neisseria gonorrhoeae: correlation of coagglutination serogroup WII with homosexually acquired infection. British Journal of Venereal Diseases 1984; 60:302-5.

12 Bygdeman S, Danielsson D, Sandstrom E. Serological classification of Neisseria gonorrhoeae by coagglutination: a study of serological patterns in two geographical areas of Sweden. Acta Derm Venereol (Stockh) 1981;61:423-7.

13 Tam MR, Buchanan TM, Sandstrom EG, et al. Serological classification of Neisseria gonorrhoeae with monoclonal antibodies. Infect Immun 1982;36:1042-53.

14 Sandstrom E, Lindell P, Harfast B, Blomberg F, Ryden A-C, Bygdeman S. Evaluation of a new set of Neisseria gonorrhoeae serogroup W-specific monoclonal antibodies for serovar determination. In: Schoolnik GK, Brooks GF, Falkow S, et al, eds. The pathogenic neisseriae. Washington DC: American Society for Microbiology, 1985:26-30.

15 Bygdeman SM, Gillenius E-C, Sandstrom EG. Comparison of two different sets of monoclonal antibodies for the serological classification of Neisseria gonorrhoeae. In: Schoolnik GK, Brooks GF, Falkow S, et al, eds. The pathogenic neisseriae. Washington DC: American Society for Microbiology, 1985: 31-6.

16 Bygdeman SM. Polyclonal and monoclonal antibodies applied to the epidemiology of gonococical infection. In: Young $\mathbf{H}$, McMillan A, eds. Immunological diagnosis of sexually transmitted diseases. New York: Marcel Dekker, 1987:117-65.

17 Young H. Cultural diagnosis of gonorrhoea with modified New York City (MNYC) medium. British Journal of Venereal Diseases 1978;54:36-40.

18 Young H, Paterson IC, McDonald DR. Rapid carbohydrate utilisation test for the identification of Neisseria gonorrhoeae. British Journal of Venereal Diseases 1976;52:172-5.

19 Kellogg DS Jr, Peacock WL Jr, Deacon WE, Brown L, Pirkle CI. Neisseria gonorrhoeae. I. Virulenoe genetically linked to colonial variation. J Bacteriol 1963;85:1274-9.

20 Sandstrom E, Tam M, Bygdeman S. Antigenic drift of gonococcal protein I as judged by serovar determination. In: Schoolnik GK, Brooks GF, Falkow S, et al, eds. The pathogenic neisseriae. Washington DC: American Society for Microbiology, 1985:13-9.

21 Danielsson D, Bygdeman S, Kallings I. Epidemiology of gonorrhoea. Serogroup, antibiotic susceptibility and auxotype patterns of consecutive gonococcal isolates from ten different areas of Sweden. Scand J Infect Dis 1983;15:33-42.

22 Whittington :WL, Vernon A, Biddle JW, et al. Serological classification of Neisseria gonorrhoeae: uses at the community level. In: Schoolnik GK, Brooks GF, Falkow S, et al, eds. The pathogenic neisseriae. Washington DC: American Society for Microbiology, 1985:20-5.

23 Kohl PK, Knapp JS, Hofmann H, et al. Epidemiological analysis of Neisseria gonorrhoeae in the Fèderal Republic of Germany by auxotyping and serological classification using monoclonal antibodies. Genitourin Med 1986;62:145-50.

24 Knapp JS, Tam MR, Novinski RC, Holmes KK, Sandstrom EG. Serological classification of Neisseria gonorrhoeae with use of monoelonal antibodies to gonococcal outer membrane protein I. J Infect Dis 1984;150:44-8.

25 Bygdeman S. Gonorrhoea in men with homosexual contacts: serogroups of isolated gonococcal strains related to antibiotic susceptibility, site of infection, and symptoms. British Journal of Venereal Diseases 1981;57:320-4.

26 Knapp JS, Sandstrom EG, Holmes KK. Overview of epidemio- 
logical and clinical applications of auxotype/serovar classification of Neisseria gonorrhoeae. In: Schoolnik GK, Brooks GF, Falkow S, et al, eds. The pathogenic neisseriae. Washington DC: American Society for Microbiology, 1985:6-12.

27 Backman M, Ruden A-K, Bygdeman SM, Jonson A, Ringertz O, Sandstrom EG. Gonococcal serovar distribution in Stockholm with special reference to multiple infections and infected partners. Acta Pathol Microbiol Scand [B] 1985;93:225-32.

28 Ruden A-K, Werner YK, Ringertz O, Bygdeman SM, Backman $M$, Sandstrom EG. Use of gonococcal W serogrouping in the evaluation of a clinical trial of rosoxacine. Sex Transm Dis 1985;12:19-24.

29 Bygdeman S, Mårdh P-A, Sandstrom E. Susceptibility of Neisseria gonorrhoeae to rifampicin and thiamphenicol. Correlation to protein I antigenic determinants. Sex Transm Dis 1984;11:366-70.

30 Ramsdedt K, Hallhagen G, Bygdeman S, et al. Serological classification and contact tracing in the control of microepidemics with $\beta$-lactamase producing Neisseria gonorrhoeae. Sex Transm Dis 1985;12:209-14. 